\title{
Establishment of immortalized Schwann cells from Fabry mice and their low uptake of recombinant $\alpha$-galactosidase
}

\author{
Ikuo Kawashima - Kazuhiko Watabe - Youichi Tajima · Tomoko Fukushige • \\ Tamotsu Kanzaki - Takuro Kanekura - Kanako Sugawara · Naho Ohyanagi · \\ Toshihiro Suzuki $\cdot$ Tadayasu Togawa $\cdot$ Hitoshi Sakuraba
}

Received: 3 September 2007 / Accepted: 9 October 2007 / Published online: 27 October 2007

(C) The Japan Society of Human Genetics and Springer 2007

\begin{abstract}
Peripheral neuropathy is one of the important manifestations of Fabry disease. Enzyme replacement therapy with presently available recombinant $\alpha$-galactosidases does not always improve the Fabry neuropathy. But the reason has not been determined yet. We established a Schwann cell line from Fabry mice, characterized it, and then examined the uptake of $\alpha$-galactosidase by cells and its effect on the degradation of accumulated substrate. The cells exhibited a distinct Schwann cell morphology and biochemical phenotype ( $\alpha$-Galactosidase activity was deficient, and numerous cytoplasmic inclusion bodies were present in the cells). A recombinant $\alpha$-galactosidase added to the culture medium was incorporated into the cultured Fabry Schwann cells dose dependently. But the increase in cell-associated enzyme activity was less than that in the
\end{abstract}

I. Kawashima · Y. Tajima

Department of Clinical Genetics, The Tokyo Metropolitan Institute of Medical Science, Tokyo Metropolitan Organization for Medical Research, Tokyo, Japan

I. Kawashima $\cdot$ Y. Tajima $\cdot$ H. Sakuraba

Japan Science and Technology Agency, CREST,

Kawaguchi, Japan

K. Watabe

Department of Molecular Neuropathology, Tokyo Metropolitan Institute for Neuroscience, Tokyo Metropolitan Organization

for Medical Research, Tokyo, Japan

T. Fukushige $\cdot$ T. Kanzaki · T. Kanekura

Department of Dermatology, Kagoshima University Graduate

School of Medicine, Kagoshima, Japan

K. Sugawara - N. Ohyanagi - T. Suzuki - T. Togawa ·

H. Sakuraba $(\bowtie)$

Department of Analytical Biochemistry, Meiji Pharmaceutical

University, 2-522-1 Noshio, Kiyose, Tokyo 204-8588, Japan

e-mail: sakuraba@my-pharm.ac.jp cases of human and mouse Fabry fibroblasts. The administration of a high dose of the enzyme improved the pathological changes in cells, although a low dose of it did not. Cellular uptake of the enzyme was strongly inhibited in the presence of mannose 6-phosphate. This suggests that the enzyme is incorporated via cation-independent mannose 6-phosphate receptors in Schwann cells. The low expression of cation-independent mannose 6-phosphate receptors in Schwann cells must be one of the reasons their uptake of the present enzymes was low. The administration of a high dose of the enzyme or the development of an enzyme containing many mannose 6-phosphate residues is required to improve Fabry neuropathy.

Keywords Fabry disease - Schwann cell . $\alpha$-Galactosidase · Globotriaosylceramide . Enzyme replacement therapy .

Cation-independent mannose 6-phosphate receptor

\begin{tabular}{|c|c|}
\hline \multicolumn{2}{|c|}{ List of abbreviations } \\
\hline ERT & enzyme replacement therapy \\
\hline PCR & polymerase chain reaction \\
\hline RT & reverse transcription \\
\hline P0 & peripheral myelin protein- 0 \\
\hline GAP43 & growth-associated protein 43 \\
\hline CGT & $\begin{array}{l}\text { UDP-galactose ceramide } \\
\text { galactosyltransferase }\end{array}$ \\
\hline MAL & myelin and lymphocyte protein \\
\hline GAPDH & glyceraldehyde 3-phosphate dehydrogenase \\
\hline GFAP & glial fibrillary acidic protein \\
\hline M6P & mannose 6-phosphate \\
\hline PBS & phosphate-buffered saline \\
\hline C-I M6PR & $\begin{array}{l}\text { cation-independent mannose 6-phosphate } \\
\text { receptor }\end{array}$ \\
\hline
\end{tabular}




\section{Introduction}

Fabry disease (MIM 301500) is a genetic disorder caused by a deficiency of lysosomal $\alpha$-galactosidase (EC 3.2.1.22) (Desnick et al. 2003). The enzymatic defect causes the progressive accumulation of globotriaosylceramide in various organs and tissues, which results in clinical manifestations, including pain in the peripheral extremities, acroparesthesia, disorders of the autonomic nervous system, angiokeratoma, hypohidrosis, corneal opacity, gastrointestinal symptoms, and renal, cardiac, and systemic vascular diseases.

Recently, recombinant human $\alpha$-galactosidases produced in mammalian cells were developed for enzyme replacement therapy (ERT) for Fabry disease (Schiffmann et al. 2000; Eng et al. 2001a, 2001b). One of them, agalsidase beta produced in Chinese hamster ovary cells, has been reported to be well incorporated into microvascular cells and to degrade endothelial deposits of globotriaosylceramide in the kidneys, heart, and skin in patients with Fabry disease (Eng et al. 2001b). However, ERT with a recombinant enzyme does not always improve the peripheral neuropathy (Eng et al. 2001b; Hilz et al. 2004). As the painful peripheral neuropathy seriously affects the quality of life of patients with Fabry disease, improved incorporation of $\alpha$-galactosidase into the peripheral nervous system is desired.

In this study, we established a spontaneously immortalized Schwann cell line from dorsal root ganglia and peripheral nerves of Fabry mice and investigated their uptake of agalsidase beta and the effect of the incorporated enzyme on the degradation of intracellularly accumulated substrate.

\section{Materials and methods}

Animals and cell culture

C57BL/6 Fabry mice produced by targeting of the Gla gene, which encodes mouse $\alpha$-galactosidase (Oshima et al.1997), were used in this experiment according to the rules drawn up by the animal care committee of our institute. Primary and long-term cultures of dorsal root ganglia and adjacent peripheral nerves derived from Fabry mice were performed according to the method previously described (Watabe et al. 1990, 1995). After 6 months in culture, spontaneously emerging colonies were isolated using cloning rings and expanded further. Among them, a Schwann cell line established from a Fabry mouse (1089C1) was cultured in Iscove's modified Dulbecco's minimum essential medium containing $5 \%$ fetal calf serum, $50 \mathrm{U} / \mathrm{mL}$ penicillin, and $50 \mu \mathrm{g} / \mathrm{mL}$ streptomycin at $37^{\circ} \mathrm{C}$ under $5 \% \mathrm{CO}_{2}$. For immunofluorescence and electron microscopy, cells were seeded on poly-L-lysine-coated $9 \mathrm{~mm}$ ACLAR round coverslips (Allied Fibers and Plastics, Pottsville, PA, USA) at a density of $1-2 \times 10^{4}$ cells per coverslip. A Schwann cell line, IMS32 (Watabe et al. 1995), derived from a CD-1 (ICR) wild-type mouse was used as a control. Cultured skin fibroblasts from a patient with Fabry disease (F377), a healthy subject (F592), a Fabry mouse (F666), and a wild-type mouse (F665) were established and cultured in Ham's F-10 medium containing $10 \%$ fetal calf serum and antibiotics under $5 \% \mathrm{CO}_{2}$. The ethical committee of our institute approved the study involving the cultured human fibroblasts, and they were obtained with agreement of the patient and the control subject.

Polymerase chain reactions for determination of the genotype and identification of Schwann-cell-associated molecules

Confirmation of the genotype of the established cultured mouse Schwann cells was performed by means of polymerase chain reactions (PCR). The sequences of the genomic PCR primers were as follows: AGALA1, 5' GGATTTATGCAGATGTTGGG-3' (exon 3, forward); AGALA2,5'-TGGCTAGACCTTTTACTTGG-3' (intron 3, reverse); pMC1neopAF, 5'-TCATCTCACCTTGCTC CTGC-3' (neo, forward); and pMC1neopAR, 5'-TATGTCCTGATAFCGGTCCG- $3^{\prime}$ (neo, reverse). The PCRs comprised 30 cycles of $95^{\circ} \mathrm{C}$ for $1 \mathrm{~min}, 55^{\circ} \mathrm{C}$ for $1.5 \mathrm{~min}$, and $72^{\circ} \mathrm{C}$ for 1.5 min with a combination of primers, AGALA1/AGALA2 (AGALA1/2), AGALA1/pMC1neopAR, or pMC1neopAF/pMC1neopAR (pMC1neopAF/R).

Reverse transcription (RT) followed by PCR was performed to identify Schwann-cell-associated molecules, i.e., $\mathrm{S} 100, \mathrm{p} 75^{\mathrm{NTR}}$, L1, peripheral myelin protein-0 (P0), growth-associated protein 43 (GAP43), UDP-galactose ceramide galactosyltransferase (CGT), and myelin and lymphocyte protein (MAL), as described elsewhere (Watabe et al. 2001, 2003). The mouse glyceraldehyde 3phosphate dehydrogenase (GAPDH) gene, a ubiquitously expressed housekeeping gene, was used as an internal marker of mRNA integrity (forward; 5'-GTCTTCACCACCATGGAGAA- ${ }^{\prime}, \quad$ reverse; 5'-GCTTCACCAC CTTCTTGATG- $3^{\prime}$ ).

Immunocytochemical analysis of Schwann-cellassociated markers

To characterize the established cultured Schwann cells, immunocytochemical analysis of S100, p $75^{\mathrm{NTR}}$, and glial 
fibrillary acidic protein (GFAP) was performed, as described previously (Watabe et al. 1995, 2003).

Assaying of $\alpha$-galactosidase activity and protein determination

$\alpha$-Galactosidase activity was measured fluorometrically with 4-methylumbelliferyl- $\alpha$-D-galactopyranoside (Calbiochem, San Diego, CA, USA) as a substrate in the presence of $N$-acetylgalactosamine (Sigma, St Louis, MO, USA) as a specific inhibitor of $\alpha-N$-acetylgalactosaminidase, according to the method previously reported (Mayes et al. 1981). Protein determination was performed with a Bio-Rad dyebinding assay kit (Bio-Rad, Hercules, CA) using bovine serum albumin as a standard.

Administration of agalsidase beta to cultured mouse Fabry Schwann cells, cultured mouse wild-type Schwann cells, cultured mouse Fabry fibroblasts, and cultured human Fabry fibroblasts

To examine the uptake of a recombinant $\alpha$-galactosidase by cultured mouse Fabry Schwann cells, cultured mouse wildtype Schwann cells, cultured mouse Fabry fibroblasts, and cultured human Fabry fibroblasts, agalsidase beta was added to the culture medium of the cells to give concentrations of $0,1.0$, and $3.0 \mu \mathrm{g} / \mathrm{mL}$. Furthermore, the mouse Fabry Schwann cells were cultured in the medium containing $10.0 \mu \mathrm{g} / \mathrm{mL}$ of the enzyme. For examination of the inhibitory effect of mannose 6-phosphate (M6P) on the cellular uptake of agalsidase beta, the cells were cultured in medium containing $5 \mathrm{mmol} / \mathrm{L} \quad \mathrm{M} 6 \mathrm{P}$ and $3.0 \mu \mathrm{g} / \mathrm{mL}$ agalsidase beta. After 24-h culture, the cells were harvested mechanically, washed three times with phosphate-buffered saline (PBS), $\mathrm{pH} \mathrm{7.4,} \mathrm{and} \mathrm{then} \mathrm{collected} \mathrm{as} \mathrm{a} \mathrm{pellet} \mathrm{by}$ centrifugation. An appropriate amount of water was then added to the pellet, and the cells were ultrasonicated. The resulting homogenate was used for the $\alpha$-galactosidase assay and protein determination.

\section{Electron microscopy}

A morphological study was performed to examine the effect of agalsidase beta on the degradation of globotriaosylceramide accumulated in cultured mouse Fabry Schwann cells. Cells were cultured in six-well plates with medium containing 3.0 and $10.0 \mu \mathrm{g} / \mathrm{mL}$ agalsidase beta for $24 \mathrm{~h}$. Then, the cells were washed and subjected to electron microscopic examination. The cells were fixed in PBS containing $2.5 \%$ glutaraldehyde and $2 \%$ paraformaldehyde, postfixed in $2 \%$ osmium tetroxide, dehydrated through a graded ethanol series, and embedded in Epon 812. Ultrathin sections were mounted on copper grids, contrasted with uranyl acetate and lead citrate, and finally examined under an electron microscope (Hitachi H-7100; Hitachi, Tokyo, Japan) (Kanzaki et al. 1989).

\section{Western blot analysis}

To determine the expression of cation-independent M6P receptor (C-I M6PR; C-I M6PR is known to be the same protein as insulin-like growth-factor-II receptor) (Tong et al.1988) in human tissues, a Western blot analysis was performed using commercially available Insta-Blot Human tissues (Imgenex, San Diego, CA, USA) as samples, according to the method described previously (Tajima et al. 2007). The human tissues (each $20 \mu \mathrm{g}$ protein) were separated on gels and transferred to a blot. Then, the blot was simultaneously reacted with goat polyclonal antibodies to human C-I M6PR (1:500 diluted) ( $\mathrm{R}$ and D systems, Minneapolis, MN, USA) and a mouse monoclonal antibody to actin clone $\mathrm{C} 4$ (1:500 diluted) (Chemicon, Temecula, CA, USA) as an internal control. Then, the blot was reacted with peroxidase-conjugated donkey anti-goat secondary antibodies (Jackson ImmunoResearch, West Grove, PA, USA) and with peroxidase-conjugated donkey anti-mouse IgG secondary antibodies (Amersham Pharmacia Biotech, Arlington Heights, IL, USA). Finally, the blot was developed with enhanced chemiluminsecence (ECL) (Amersham Pharmacia Biotech) as a chemiluminescent substrate on Hyperfilm ${ }^{\mathrm{TM}}$ ECL (Amersham Pharmacia Biotech).

\section{Results}

Characterization of the established Schwann cells derived from a Fabry mouse

Schwann cell lines established from Fabry and wild-type mice were spindle-shaped and not contact-inhibited. To determine the genotype of the established Schwann cells, those designated as 1089C1 and IMS32 cells, respectively, were used as representatives in this study. A genomic DNA fragment of $452 \mathrm{bp}$ was amplified by means of PCR with the primer pair of AGALA1/2 for the wild-type locus and $1,250 \mathrm{bp}$ and $368 \mathrm{bp}$ DNA fragments with those of AGALA1/pMC1neopAR and pMCneopAF/R, respectively, for the targeted locus. As shown in Fig. 1, both the 1,250-bp and 368-bp DNA fragments for the targeted locus were detected for $1089 \mathrm{C} 1$, whereas a 452-bp band for the wild-type locus was observed for IMS32. The results 


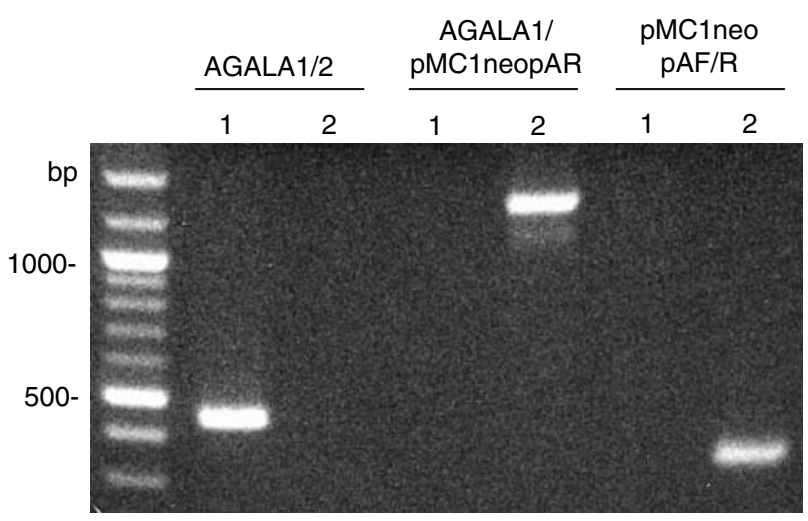

Fig. 1 Genomic polymerase chain reaction analysis of $\alpha$-galactosidase. Lane 1, wild-type mouse IMS32 Schwann cells; lane 2, Fabry mouse 1089C1 Schwann cells. Primer pairs AGALA1/2 and $\mathrm{pMC} 1$ neoAF/R gave amplified products corresponding to exon 3 of the $\alpha$-galactosidase gene (a 452-bp product) in IMS32 cells and a neogene-expression cassette inserted into exon 3 (a 368-bp product) of the $\alpha$-galactosidase gene in $1089 \mathrm{C} 1$ cells, respectively. Primer pairs AGALA1/pMC1neoAR yielded a 1,250-bp product corresponding to the disrupted $\alpha$-galactosidase gene followed by a neo-gene-expression cassette in $1089 \mathrm{C} 1$ cells. Markers (left side) $=100$-bp DNA size markers

showed that the Gla gene of $1089 \mathrm{C} 1$ is disrupted and contained a neo-gene-expression cassette (Oshima et al. 1997).

RT-PCR analysis demonstrated mRNA expression of Schwann-cell-associated molecules, S100, $\mathrm{p}^{\mathrm{NTR}}$, L1, P0, GAP43, CGT, and MAL in 1089C1 cells (Fig. 2a), whereas they were hardly detected in Fabry mouse fibroblasts (F666 cells) (Fig. 2b). The 1089C1 cells were intensely immunostained for $\mathrm{S} 100, \mathrm{p} 75^{\mathrm{NTR}}$ and GFAP (Fig. 3). These results indicate the distinct Schwann cell phenotype of $1089 \mathrm{C} 1$ cells.

$\alpha$-Galactosidase activity in cultured mouse Fabry Schwann cells $(1089 \mathrm{C} 1)$ was about $1 \%$ of the control value (Table 1). An electron-microscopic study revealed cytosolic lamellar inclusion bodies in $1089 \mathrm{C} 1$ cells, showing the membranous accumulation of undegraded globotriaosylceramide that is characteristic of Fabry disease (Fig. 4b).

These inclusion bodies were not seen in IMS32 cells (Fig. 4a).

Enzyme replacement effect of agalsidase beta on cultured mouse Fabry Schwann cells and cultured mouse and human Fabry fibroblasts

The uptake of the recombinant $\alpha$-galactosidase, agalsidase beta, by mouse Schwann cells (1089C1) was investigated and compared with that by mouse (F666) and human (F377) Fabry fibroblasts. As shown in Table 1, the cell-associated $\alpha$ -

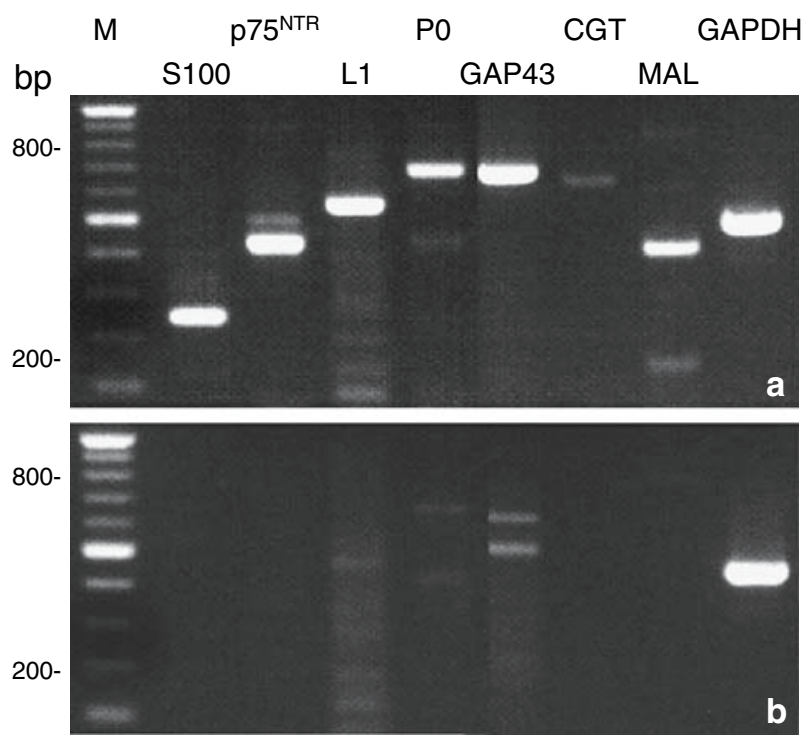

Fig. 2 Real-time polymerase chain reaction (RT-PCR) analysis of Schwann-cell-associated markers in cultured mouse Schwann cells and cultured mouse fibroblasts. a 1089C1 cells; b F666 cells. The amplified PCR fragments were S100 (247 bp), p75 ${ }^{\text {NTR }}$ (432 bp), L1 (577 bp), P0 (692 bp), GAP43 (681 bp), CGT (653 bp), MAL (416 bp), and GAPDH (489 bp). $M=100$-bp DNA size markers

galactosidase activity increased dose dependently when the cells were cultured in culture medium containing agalsidase beta for $24 \mathrm{~h}$. Dose dependence was detected up to $30 \mu \mathrm{g} / \mathrm{mL}$ (data not shown). The increase in the enzyme activity was lower in the Schwann cells than in the fibroblasts. The uptake of the recombinant $\alpha$-galactosidase by mouse Fabry Schwann cells was strongly inhibited in the presence of $5 \mathrm{mmol} / \mathrm{L}$ M6P in the culture medium (Table 1).

The effect of incorporated agalsidase beta on the clearance of intracellular inclusion bodies resulting from the accumulation of globotriaosylceramide in 1089C1 cells was morphologically investigated. A decrease in the number of inclusion bodies was not observed after $24 \mathrm{~h}$ in the culture medium containing $3.0 \mu \mathrm{g} / \mathrm{mL}$ agalsidase beta (data not shown), although intracellularly deposited globotriaosylceramide was apparently decreased in the case of cultured Fabry fibroblasts (F377), as described previously (Sakuraba et al. 2006a, 2006b). The administration of a high dose $(10.0 \mu \mathrm{g} / \mathrm{mL})$ of the enzyme apparently decreased the number of inclusion bodies in the cells (Fig. 4c).

Expression of C-I M6PR in human tissues

The results of Western blotting for C-I M6PR in human tissues are shown in Fig. 5. Bands corresponding to the $250 \mathrm{kDa}$ C-I M6PR and the $42 \mathrm{kDa}$ actin were detected for the brain (lane 1), kidney (lane 2), and liver (lane 3) tissues. However, the amount of expressed C-I M6PR protein in the 
Fig. 3 Phase-contrast and immunofluorescence microscopy of $1089 \mathrm{C} 1$ cells. a Phase-contrast microscopy; b immunofluorescence of S100; c p $75^{\mathrm{NTR}} ; \mathbf{d}$ GFAP. Scale bars $=50 \mu \mathrm{m}$
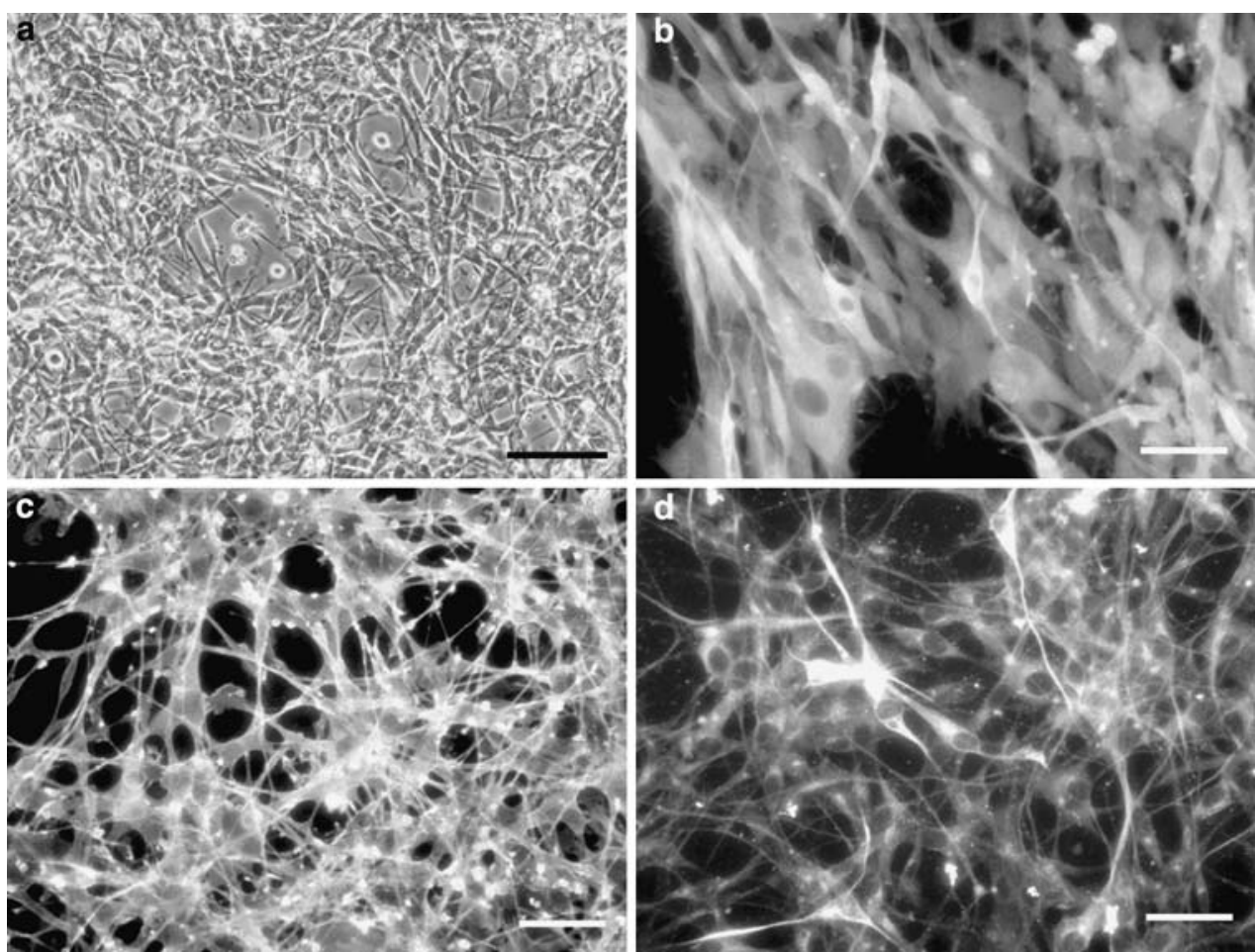

brain was apparently smaller than that in the kidney and liver tissues.

\section{Discussion}

Two different human recombinant $\alpha$-galactosidases, agalsidase alfa $\left(\right.$ Replagal $^{\circledR}$; Shire, Basingstoke, UK) and agalsidase beta (Fabrazyme ${ }^{\circledR}$; Genzyme, Cambridge, MA, USA), have been developed for ERT for Fabry disease. Agalsidase alfa, produced in cultured human fibroblasts, has been approved in Europe and Japan, and the use of $0.2 \mathrm{mg} / \mathrm{kg}$ body weight is recommended for Fabry patients. On the other hand, agalsidase beta, generated in cultured Chinese hamster ovary cells, has been approved in Europe, USA, and Japan, and the use of $1.0 \mathrm{mg} / \mathrm{kg}$ body weight is

Table 1 Cell-associated $\alpha$-galactosidase activity in cultured mouse Schwann cells and cultured mouse and human fibroblasts after the addition of various doses of agalsidase beta to the culture medium

\begin{tabular}{|c|c|c|c|c|c|}
\hline & \multicolumn{5}{|c|}{ Agalsidase beta $(\mu \mathrm{g} / \mathrm{mL})$} \\
\hline & 0 & 1.0 & 3.0 & 3.0 & 10.0 \\
\hline M6P (5 mmol/L) & - & - & - & + & - \\
\hline \multicolumn{6}{|l|}{ Mouse Schwann cells } \\
\hline Fabry $(1089 \mathrm{C} 1)$ & 5.0 & 90 & $0.29 \times 10^{3}$ & 6.0 & $1.1 \times 10^{3}$ \\
\hline Wild-type (IMS32) & $0.49 \times 10^{3}$ & $0.66 \times 10^{3}$ & $0.79 \times 10^{3}$ & - & - \\
\hline \multicolumn{6}{|l|}{ Mouse fibroblasts } \\
\hline Fabry (F666) & 1.0 & $1.3 \times 10^{3}$ & $2.1 \times 10^{3}$ & 63 & - \\
\hline Wild-type (F665) & 93 & $1.1 \times 10^{3}$ & $2.5 \times 10^{3}$ & - & - \\
\hline \multicolumn{6}{|l|}{ Human fibroblasts } \\
\hline Fabry (F377) & 2.0 & $3.9 \times 10^{3}$ & $5.8 \times 10^{3}$ & 73 & - \\
\hline Wild-type (F592) & 36 & $3.1 \times 10^{3}$ & $4.7 \times 10^{3}$ & - & - \\
\hline
\end{tabular}

Mouse Schwann cells (IMS32 and 1089C1), mouse fibroblasts (F665 and F666), and human fibroblasts (F377 and F592) were cultured in medium containing various doses of agalsidase beta, as described under "Materials and methods". 1089C1, F666, and F377 were cultured in medium containing $3.0 \mu \mathrm{g} / \mathrm{mL}$ agalsidase beta in the presence of $5 \mathrm{mmol} / \mathrm{L}$ mannose 6-phosphate. After 24-h culture, the cells were harvested and the cell-associated $\alpha$-galactosidase activity was measured

Cell-associated $\alpha$-galactosidase activity is expressed as $\mathrm{nmol} / \mathrm{h} \times \mathrm{mg}$ protein

- , not applicable in table with the exception of M6P column. In M6P column +, added; -, did not add 
Fig. 4 Morphological effect of the administration of agalsidase beta on $1089 \mathrm{C} 1$ cells. a Wildtype mouse Schwann cell line (IMS32). Scale bar $=2 \mu \mathrm{m}$. b Fabry mouse Schwann cell line (1089C1). Scale bar $=2 \mu \mathrm{m}$. c 1089C1 treated with $10.0 \mu \mathrm{g} /$ $\mathrm{mL}$ agalsidase beta for $24 \mathrm{~h}$. Scale bar $=2 \mu \mathrm{m}$
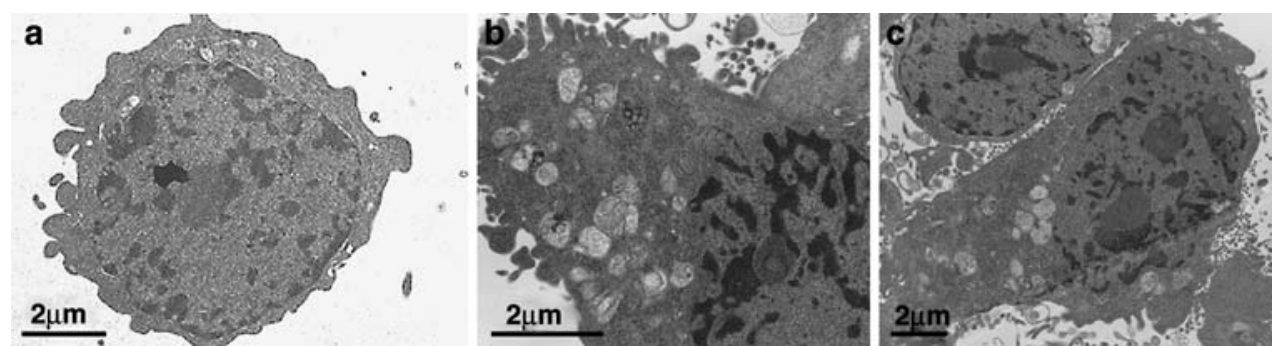

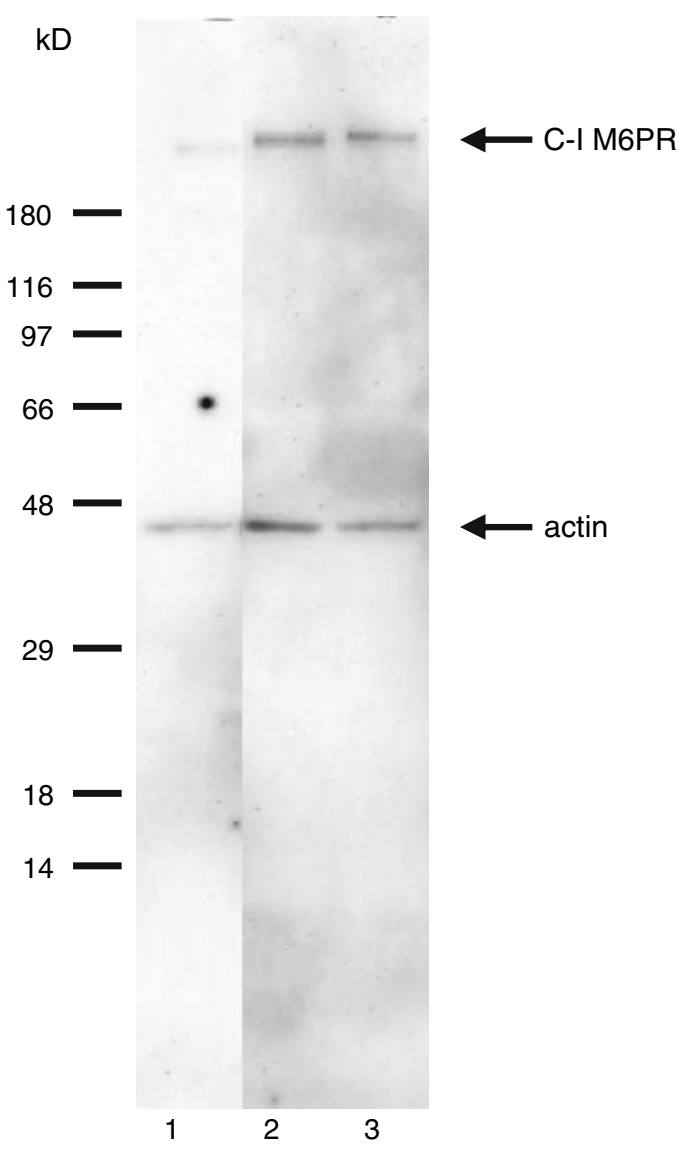

Fig. 5 Western blotting of C-I mannose 6-phosphate receptor (M6PR). The expression of C-I M6PR in human tissues, including brain, kidney, and liver, was examined by means of Western blotting. Actin was used as an internal control. Lane 1, brain; lane 2, kidney; lane 3, liver

recommended. Comparative studies on agalsidase alfa and agalsidase beta revealed that agalsidase beta contains a higher level of M6P (3.1 mmol/mol protein) than does agalsidase alfa $(1.8 \mathrm{mmol} / \mathrm{mol}$ protein), although the protein sequence is the same for the two products (Lee et al. 2003).

Eng et al. (2001b) reported that microvascular endothelial deposits of globotriaosylceramide were remarkably decreased by ERT with agalsidase beta but that no significant difference was observed in regard to improvement in neuropathy between Fabry patients treated with agalsidase beta and those treated with a placebo. Schiffmann et al. (2006) reported the autopsy results for a 47-year-old man who was on ERT for more than 2 years before he died. They revealed that repeated infusions with agalsidase beta over a prolonged period did not appreciably remove storage material from tissues, including dorsal root ganglia, other than vascular endothelial cells. Hilz et al. (2004) reported that ERT with agalsidase beta improved the Fabry neuropathy, but a lack of recovery in some patients with abnormal cold or heat pain perception was found. These findings suggest low uptake of the recombinant $\alpha$-galactosidase by neural cells.

Lysosomal enzymes including $\alpha$-galactosidase are known to be synthesized in the rough endoplasmic reticulum and are modified through the addition of sugar chains. Then they are transferred to the Golgi apparatus, where the addition of M6P residues to the nonreducing ends of the sugar chains occurs, and are transported to endosomes through a C-I M6PR (Dahms et al. 1989). The enzymes could also be incorporated into various types of cells via CI M6PRs on the surface of the cells.

In this study, we established a spontaneously immortalized Schwann cell line, 1089C1, from Fabry mice. It has a disrupted Gla gene allele and exhibits a distinct Schwann cell morphology and biochemical phenotype. Enzyme assays revealed a deficiency of $\alpha$-galactosidase activity, and cytoplasmic lamellar inclusion bodies were found in the cells, these being biochemical and pathological characteristics of Fabry disease.

Pathological analyses revealed that globotriaosylceramide was deposited in neurons, Schwann cells, and perineural sheath cells of peripheral nerves (Desnick et al. 2001), and the accumulation of globotriaosylceramide must affect the peripheral nervous system, resulting in Fabry neuropathy. A recombinant $\alpha$-galactosidase, agalsidase beta, added to the culture medium of mouse Fabry Schwann cells was incorporated dose dependently. But the increase in cell-associated $\alpha$-galactosidase activity was less than that in the cases of mouse and human Fabry fibroblasts. Intracellular inclusion bodies in mouse Fabry Schwann cells could not be cleaved even on the addition of $3.0 \mu \mathrm{g} / \mathrm{mL}$ agalsidase beta, although this is 
completely sufficient to remove the storage materials from human Fabry fibroblasts (Sakuraba et al. 2006a, 2006b).

As the uptake of the enzyme was strongly inhibited by the addition of M6P to the culture medium for both cultured Schwann cells and cultured fibroblasts, it is thought that the recombinant $\alpha$-galactosidase was incorporated mainly via C-I M6PRs on the cell membrane. To examine the expression of C-I M6PRs in nervous tissues, we performed Western blotting analysis of C-I M6PRs using human tissues, including brain, kidney, and liver as samples. Unfortunately, we could not obtain human peripheral nervous tissues. The antibody, which is available for Western blotting, is that raised to human C-I M6PR and does not cross-react mouse C-I M6PR. So, we used human brain tissues, including neuron, oligodendroglia, and astroglia, as samples for Western blotting for reference, although those tissues do not contain Schwann cells. The results revealed that the expression of C-I M6PRs in the neural tissue is lower than in the kidney and liver tissues. The low expression of C-I M6PRs in neural cells, including Schwann cells, must be one reason their uptake of the enzyme is low and is not effective for the peripheral neuropathy in Fabry disease.

In conclusion, we established a cultured Schwann cell line from Fabry mice and investigated the uptake of a recombinant $\alpha$-galactosidase, agalsidase beta, in comparison with that by cultured mouse and human Fabry fibroblasts. The experiment revealed the low uptake of the enzyme into the Schwann cells. To improve ERT for Fabry neuropathy, we should develop a recombinant $\alpha$-galactosidase containing many M6P residues.

Acknowledgments We wish to thank Drs. Ashok B. Kulkarni (Gene Targeting Faculty and Functional Genomics Unit, NIDCR, $\mathrm{NIH}$ ) and Toshio Oshima (Laboratory for Development Neurology, Brain Science Institute, RIKEN) for providing us with the Fabry mice. This work was partly supported by the Japan Society for the Promotion of Science, the Ministry of Education, Science, Sports and Culture, the Ministry of Health, Labor and Welfare of Japan, the Japan Science and Technology Agency, and CREST. This work was partly supported by grants from the Japan Society for Promotion of Science, the Ministry of Education, Science, Sports and Culture of Japan, the Ministry of Health, Labor and Welfare of Japan, the Japan Science and Technology Agency, and CREST.

\section{References}

Dahms NM, Lobel P, Kornfeld S (1989) Mannose 6-phosphate receptor and lysosomal enzyme targeting. J Biol Chem 264:12115-12118

Desnick RJ, Ioannou YA, Eng CM (2001) $\alpha$-Galactosidase A deficiency: Fabry disease. In: Scriver CR, Beaudet AL, Sly WS, Valle D (eds) The metabolic and molecular bases of inherited disease, 8th edn. McGraw-Hill, New York, pp 37333774
Desnick RJ, Brady RO, Barranger J, Collins AJ, Germain DP, Goldman M, Grabowski G, Packman S, Wilcox WR (2003) Fabry disease, an under-recognized multisystemic disorder: expert recommendations for diagnosis, management, and enzyme replacement therapy. Ann Intern Med 138:338-346

Eng CM, Banikzzemi M, Gordon RE, Goldman M, Phelps R, Kim L, Gass A, Winston J, Dikman S, Fallon JT, Brodie S, Stacy CB, Mehta D, Parsons R, Norton K, O'Callaghan M, Desnick RJ (2001a) A phase $1 / 2$ clinical trial of enzyme replacement in Fabry disease: pharmacokinetic, substrate clearance, and safety studies. Am J Hum Genet 68:711-722

Eng CM, Guffon N, Wilcox WR, Germain DP, Lee P, Waldek S, Caplan L, Linthorst GE, Desnick RJ (2001b) Safety and efficacy of recombinant human $\alpha$-galactosidase A replacement therapy in Fabry's disease. N Engl J Med 345:9-16

Hilz MJ, Brys M, Marthol H, Stemper B, Dütsch M (2004) Enzyme replacement therapy improves function of $\mathrm{C}$-, $\mathrm{A} \delta$-, and $\mathrm{A} \beta$-nerve fibers in Fabry neuropathy. Neurology 62:1066-1079

Kanzaki T, Yokota M, Mizuno N, Matsumoto Y, Hirabayashi Y (1989) Novel lysosomal glycoaminoacid storage disease with angiokeratoma corporis diffusum. Lancet 1:875-877

Lee K, Jin X, Zhang K, Copertino L, Andrews L, Baker-Malcom J, Gegan L, Qiu H, Seiger K, Barngrover D, McPherson JM, Edmunds T (2003) A biochemical and pharmacological comparison of enzyme replacement therapies for the glycolipid storage disorder Fabry disease. Glycobiology 13:305-313

Mayes JS, Scheerer JB, Sifers RN, Donaldson ML (1981) Differential assay for lysosomal $\alpha$-galactosidase in human tissues and its application to Fabry's disease. Clin Chim Acta 112:247-251

Oshima T, Murray GJ, Swaim WD, Longenecker G, Quirk JM, Cardarelli CO, Sugimoto Y, Pastan I, Gottesman MM, Brady RO, Kulkarni AB (1997) $\alpha$-Galactosidase A deficient mice: a model of Fabry disease. Proc Natl Acad Sci USA 94:2540-2544

Sakuraba H, Murata-Ohsawa M, Kawashima I, Tajima Y, Kotani M, Oshima T, Chiba Y, Takashiba M, Jigami Y, Fukushige T, Kanzaki T, Itoh K (2006a) Comparison of the effects of agalsidase alfa and agalsidase beta on cultured human Fabry fibroblasts and Fabry mice. J Hum Genet 51:180-188

Sakuraba H, Chiba Y, Kotani M, Kawashima I, Ohsawa M, Tajima Y, Takaoka Y, Jigami Y, Takahashi H, Hirai Y, Shimada T, Hashimoto Y, Ishii K, Kobayashi T, Watabe K, Fukushige T, Kanzaki T (2006b) Corrective effect on Fabry mice of yeast recombinant human $\alpha$-galactosidase with $N$-linked sugar chains suitable for lysosomal delivery. J Hum Genet 51:341-352

Schiffmann R, Murray GJ, Treco D, Daniel P, Sellos-Moura M, Myers M, Quirk JM, Zirzow GC, Borowski M, Loveday K, Anderson T, Gillespie F, Cliver KL, Jeffries NO, Doo E, Liang TJ, Kreps C, Gunter K, Frei K, Crutchfield K, Selden RF, Brady RO (2000) Infusion of $\alpha$-galactosidase A reduces tissue globotriaosylceramide storage in patients with Fabry disease. Proc Natl Acad Sci USA 97:365-370

Schiffmann R, Rapkiewicz A, Abu-Asab M, Ries M, Askari H, Tsokos M, Quezado M (2006) Pathological findings in a patient with Fabry disease who died after 2.5 years of enzyme replacement. Virchows Arch 448:337-343

Tajima Y, Matsuzawa F, Aikawa S, Okumiya T, Yoshimizu M, Tsukimura T, Ikekita M, Tsujino S, Tsuji A, Edmunds T, Sakuraba H (2007) Structural and biochemical studies on Pompe disease and "pseudodeficiency of acid alpha-glucosidase". J Hum Genet Epub, PMID: 17805474

Tong PY, Tollefsen SE, Kornfeld S (1988) The cation-independent mannose 6-phosphate receptor binds insulin-like growth factor II. J Biol Chem 263:2585-2588

Watabe K, Yamada M, Kawashima T, Kim SU (1990) Transfection and stable transformation of adult mouse Schwann cells with SV-40 large T antigen. J Neuropathol Exp Neurol 49:455-467 
Watabe K, Fukuda T, Tanaka J, Honda H, Toyohara K, Sakai O (1995) Spontaneously immortalized adult mouse Schwann cells secrete autocrine and pancrine growth-promoting activities. J Neurosci Res 41:279-290

Watabe K, Ida H, Uehara K, Oyanagi K, Sakamoto T, Tanaka J, Garver WS, Miyawaki S, Ohno K, Eto Y (2001) Establishment and characterization of immortalized Schwann cells from murine model of Niemann-Pick disease type C (spm/spm). J Peripher Nerv Syst 6:85-94

Watabe K, Sakamoto T, Kawazoe Y, Michikawa M, Miyamoto K, Yamamura T, Saya H, Araki N (2003) Tissue culture methods to study neurological disorders: establishment of immortalized Schwann cells from murine disease models. Neuropathology 23:68-78 